\title{
Some challenges in hydrometry
}

\author{
Asgeir PETERSEN-ØVERLEIR
}

Statkraft, Norway, asgeir.petersen-overleir@statkraft.com

\begin{abstract}
Hydrometry has always been an important branch in hydrology. Even so, the quality of streamflow data might not have evolved in accordance with the advances in hydrological sciences. A too large uncertainty in published data is still a challenge in hydrometry. Hydrometric field work is a diverse profession. Technical equipment and personnel competence are usually in accordance with accepted standards. Hence, there are no technical or practical reasons that should indicate that it is impossible to achieve accurate data for a particular gauging station, given that it is reasonably located in the river channel. This short note argues that two main reasons for a too large uncertainty in published data are too comprehensive hydrometric networks and no criteria for accuracy of published data. It is also argued that the chief uncertainty factor in rating curves is extrapolation uncertainty. A short description of a project in Statkraft that has been launched to minimize extrapolation of rating curves in the network owned by the company is also given.
\end{abstract}

Key-words: stage-discharge, hydrometric network, extrapolation, uncertainty

\section{Des défis pour l’hydrométrie}

RÉSUMÉ. - L'Hydrométrie a toujours été un secteur important de l'hydrologie. Pourtant la qualité des données de débit n’a pas évolué conformément aux progrès des sciences hydrologiques. La trop grande incertitude des données publiées reste un défi pour l'hydrométrie. Le domaine de l'hydrométrique recouvre une grande diversifté de professionnels. L'équipement technique et la compétence du personnel sont généralement conformes aux normes. Par conséquent, il n'y a pas de raisons techniques ou pratiques qui impliqueraient l'impossibilité d'obtenir des données précises pour une station de jaugeage particulière à partir du moment où elle est raisonnablement située dans le chenal de la rivière. Cette courte note soutient que deux raisons principales pour une trop grande incertitude dans les données publiées sont des réseaux hydrométriques trop étendus et aucun critère de précision des données publiées. Il est également mis en avant que le pricipal facteur d'incertitude dans la notation des courbes est une l'incertitude de l'extrapolation. Une brève description d'un projet de Statkraft lancé pour minimiser l'extrapolation des courbes de tarage dans le réseau de mesure appartenant à la société est également donnée.

Mots-clés : hauteur-débit, réseau hydrométrique, extrapolation, incertitude

\section{INTRODUCTION}

Papers addressing topics in hydrometry used to be rather scant in scientific hydrological literature, and very much limited to the publications made by USGS that begin to emerge around 1900. The reason for this at least twofold. Firstly, technicians working with stations have traditionally had focus on how to make the gauging stations work well, using proper field working methods and practical solutions. Ideas that the branch, and especially the topic of rating curves and the associated uncertainties, should merit scientific attention seems not to have been very common. Secondly, the scientific community in hydrology and hydraulics contributing to the scientific literature, used to have, and still has, too little knowledge about how hydrometric data is produced, and thus have not seen the scientific significance of hydrometry in hydrology and related fields. This has fortunately changed slightly during the last ten years, and especially when it comes to rating curve related studies. New methods for setting up stage-discharge relationships have been proposed in the scientific literature, and techniques for analysing rating curve uncertainty in streamflow data calculated from stage have emerged. There have also been many studies on the impact of discharge data uncertainty in subsequent hydrological and hydraulic modelling. Despite this encouraging development, there are still some areas that need more attention. One of those areas is the practice of hydrometry in official hydrological agencies, which is an issue closely related to rating curve analysis. The larger part of gauging stations is operated by national agencies, and it appears that new scientific results still is either not employed in practice, or not appreciated in the national hydrometric environments. This short paper, and especially the corresponding presentation, addresses some of the remaining challenges in hydrometry.

\section{CHALLENGES IN HYDROMETRIC PRACTICE}

\section{II.1. To publish or not to publish uncertain data}

Several official databases for hydrometric data have information on data quality accompanying the data. This is of course a good thing, given that the information is accurate, 
understandable and easily available for people interested in the data. For example, information on periods of missing data that has been filled-in is important. Data loggers and telemetric systems will always malfunction sooner or later, as well as stage sensors. Gaps in data will keep on occurring. Such incidents can of course be minimized, but not eliminated. Similarly, winter discharge data affected by ice in the hydraulic control yields uncertainties that are difficult to eliminate, since such data are often corrected and hence not directly measured. Information on ice affected periods with modelled data is therefore very important.

Large rating curve imprecision is on the other hand an unacceptable uncertainty, even if this is informed about on the database. To make the issue less comprehensive, stations affected by systematic errors related to significant channel changes or unaccounted for hysteresis due to variable backwater and unsteady flow are not included. Stations having these problems should be closed down or relocated if the responsible hydrometric offices do not improve the ratings using more complex measurement schemes. Normal gauging stations where the hydraulic control is relatively stable and having a unique stage-discharge relationship are here considered. If the rating curve is poorly measured, which in most cases means that there is a substantial degree of extrapolation going on, streamflow data should not be available on the database. I have yet not seen any hydrometric database draw the line of what is acceptable rating curve uncertainty. As presently described, deriving plausible uncertainty measures in the extrapolated area of a rating curve is extremely difficult. A user might be deceived by the accuracy of a streamflow series when common uncertainty methods are applied for data in the extrapolated area of the rating curve. In any case, there should be set a certain limit of both uncertainty and degree of extrapolation before a rating curve can be used to calculate streamflow data for logged stage data.

My experience is that as long as the data is available, users will apply the data in their analysis even if there is information stating that rating curve uncertainty is unacceptably large. The location and catchment characteristics of a particular gauging station are often very attractive for a certain application. An analyst will therefore not be deterred from using the data if the rating curve for this particular station is poorly measured. We are here talking about the balance between data accuracy and representativeness of a station. In too many cases this balance seems to tip in favour of representativeness. The consequences of using imprecise data are difficult to calculate in general. This is maybe why data uncertain discharge data is misused in all kinds of analysis. In any case, recommended standards on rating curve quality on published streamflow data should be worked out. This is in my opinion an important challenge in hydrometry.

\section{II.2. Hydrometric networks versus hydrometric personnel}

The official net of gauging stations in Norway is administered by NVE (the Norwegian Water Recourses and Energy Directorate) and comprises about 500 stations. Station maintenance, including discharge measurements, is done by around 20 field hydrologists. They always work in teams of two persons, and have roughly 10 travel working weeks (Monday to Friday) annually. Distance between stations is sometimes significant, and many stations are remote and require significant walking distances. The distance between the offices and the actual areas is typically one working day with car travel and/or flight trip. On the average, one could say that 8 stations are visited during a working week. The abovementioned numbers imply that there are, on average, performed about 2 measurements per station annually in Norway. Even if most of the stations have stable hydraulic controls, it is this clear that it takes many years before a station has a rating curve where the range of recorded stage is well covered with measurements, even if extra effort is given during periods of floods and droughts [Petersen-Øverleir et al. 2009]. Taking into account that a discharge measurement is a "blood test" on the performance of a station (unstable control, hysteresis, problems with stage measurement, etc.), it is also clear that a low measurement frequency enables problems to both happen and endure at a station [Kitandis 1984, Ibbit \& Pearson 1987].

The problem of having a too large hydrometric network compared with the size of the staff managing the stations is found in many other countries. Again, this might be classified as an issue related to the balance between representativeness, which is in this case is spatial coverage of various hydrological characteristics and operational needs [Laizé 2008]. And once more, it appears that more weight than is reasonable is given to hydrological representativeness. Papers addressing the consequences of network reduction [Pearson 1998, Spence 2007] do generally not appreciate that reduction might increase the quality of rating curves.

Essentially, the problem of poor rating curves is related to cost. Investing money in more hydrometric personnel and proper training, as well as top quality hydrometric and station related equipment, rating curve uncertainty can be virtually eliminated during a rather short period of time. In any case, the size of a hydrometric network must be in accordance with the size of the staff of hydrometrists. Standards and recommendations on are lacking, and can thus be considered as a challenge in hydrometry.

It is worth noting that this cannot be done to reduce sample variability. Here time must pass. But with excellent data quality, each year of new data becomes even more valuable.

\section{RATING CURVE EXTRAPOLATION}

A rating curve that has been set up using several measurements covering the whole range of stage observed at the station has little uncertainty, given that unaccounted for hysteretic characteristics and/or channel unstableness is negligible. Some uncertainty will however remain, especially in the low-flow part, mainly due to scatter caused by measurement imprecision and segmentation uncertainty. In such situations, the hydrological literature provides good methods for calculating the uncertainty of discharge values inferred from recorded stage time-series [Venetis 1970, Reitan \& Petersen-Øverleir 2009]. On the other hand, extrapolation beyond the area covered by measurements can lead to dramatic uncertainties. Even when faced with this chance of formidable errors, rating curves are frequently extrapolated far beyond the measured area and applied in analysis.

Assuming that the upper or lower segment of a fitted rating curve is valid in the extrapolated area, one can extrapolate the uncertainty from the measured part. Often one sees that the segmentation uncertainty, i.e. the variability in the upper segment due to where the last segmentation point is located, soon becomes very significant. The number, scatter, range and distribution of the measurements used to fit the end segments will also of course also contribute greatly to the size of the uncertainty limits. However, the largest uncertainty is in fact the chance of new and unobserved 
rating shifts in the unmeasured area. Modelling this uncertainty consistently is extremely difficult, and there exist no widely accepted methods in the literature for doing it properly. Some studies that apply theoretical hydraulics and measured channel geometry have proposed extrapolation methods that are amenable to uncertainty/sensitive analysis in the area not covered by direct measurements, e.g. [Di Baldassarre \& Claps 2011]. The statistical appropriateness of these methods, and their suitability in the study of error propagation in subsequent analysis, is however unclear. Therefore, rating curve extrapolation error may be considered as the most significant unsolved problem in rating curve uncertainty analysis.

\section{UNCERTAINTY IN LOW-FLOW DATA}

The characteristics of low-flow are central in many specialized applications, for example drought analysis which has become a rather big issue in hydrology during the last two decades. One also has to realize that low-flow in most cases occupies a large part of an annual hydrograph. Hence, accuracy in low-flow data is an important issue. The desired precision is very difficult to achieve in a natural channel. Firstly, this is due to high rating curve variability in the low part of the rating curve. Low-flow measurements are very difficult to perform since it often involves measuring in cross sections having slow and shallow flow. Measurement techniques perform poorly in such conditions. High scatter and extrapolation is therefore encountered. Channel changes which are not detectable on the remaining part of the rating curve, might become dominant at low flows. These changes contribute to the scatter, but are often random in nature and difficult to detect and to account for. Secondly, low-flow controls in natural rivers can become insensitive, and the slightest error in stage determination becomes significant. Therefore, uncertainty in low flow data recorded in natural channels is a major challenge in hydrometry. And again, one sees that papers addressing the status and challenges in low-flow hydrology, e.g. [Smakhtin, V. U. 2001], do not recognize the significance data imprecision and the means to mitigate it.

\section{RATING CURVE ASSESSMENT IN STATKRAFTS NETWORK}

Design and justification for Statkraft's hydrometric network is above all energy management. Real-time data is used to operate the catchment runoff models on a daily basis, whereas historical data is used to configure and calibrate the models and to assess time varying trends in characteristics of hydro-meteorological variables. Furthermore, subject to directions of the Norwegian Water Resources and Energy Directorate (NVE), Statkraft shall investigate and record selected regions of natural water within regulated regions. The intention of this legislation is, among other things, to provide information to the assessment of the effects of damming, abstraction, etc. in the regulated area. The injunctions do in most cases coincide with Statkraft's need for information about natural runoff in reservoir inflow forecasting.

Today Statkraft's nationwide network comprises close to 150 stations. The growth of stations was slow until 1997. A project occurring at this time, embracing most of the areas in energy management, including operational hydrology, gave an impetus to the establishment of several new stations. A subsequent assessment of the hydrometric network was performed in 2007. It pointed out that a further expansion of the hydrometric network was warranted. A project was therefore appointed to establish more stations and to renew instrumentation on the existing stations. This project ended last year.

The bulk of the stations have been design with the goal to provide data to the operational hydrological models. This involves hourly measurement of stage/discharge, precipitation, wind speed and temperature. Measurements for setting up rating curves at Statkraft stations are mostly done by NVE,
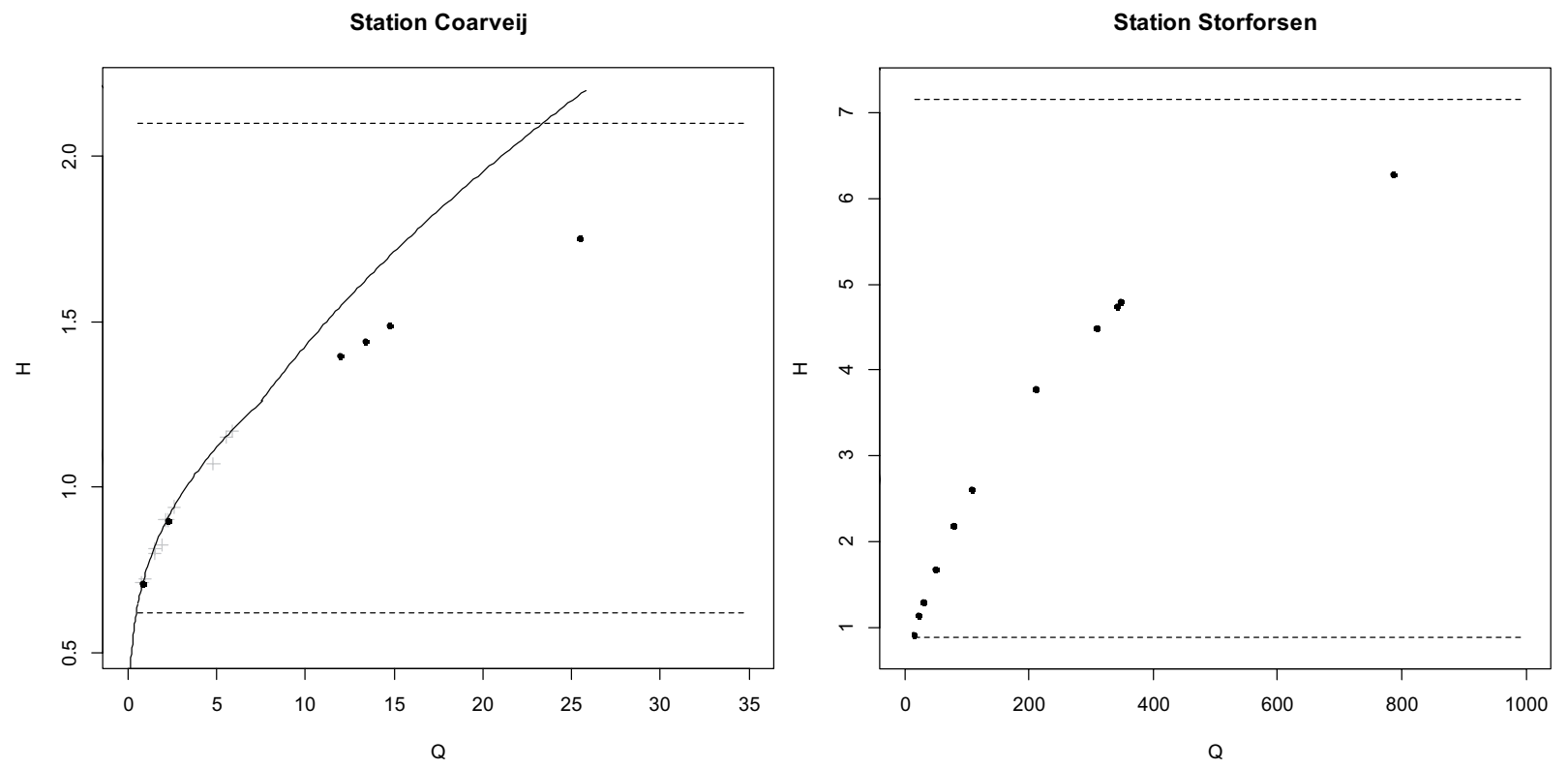

Figure 1: Measurements prior to the projects marked (grey crosses), associated rating curves and new measurements taken during the project (black dots) for two Statkraft stations. Dotted lines represent the range of stage recorded at the stations. 
which works as a consultant. The frequency of measurements used to be the same as for the stations managed by NVE. As mentioned, this resulted in too uncertain rating curves. New stations set up during the latest expansion project also needed rating curves. A project was therefore launched in 2010. The goal was to obtain the measurements needed to ensure proper rating curves and little extrapolation on 18 of the most important gauging stations. The task was put out to tender. NVE and a smaller hydrometric company, HydraTeam, were chosen as contractors. An intensive (and expensive) measurement scheme, where helicopter was heavily applied in order to capture interesting stage levels, was then launched, and results from two stations are shown in figure 1. The left hand plot illustrates a situation form the station Coarveij, where extrapolation upwards used to be based on a segment not justified by measurements but probably simple hydraulic theory. Existing measurements were normally taken during annual station control performed by NVE personnel. The Coarveij station is located in high altitudes and difficult to access. Its location made it interesting for estimating inflow to nearby reservoirs. One sees that the new measurements taken during the spring flood last year using helicopter suggest quite different flood values than the old rating curve. The right hand plot shows that nearly the whole range of stage is covered by measurements at a newly established station. It is hoped that the upper part can be covered by a couple of more measurements during the spring flood of 2013. Hence, it is believed that data from the Storforsen station can be safely applied operationally just two years after its establishment!

\section{REFERENCES AND CITATIONS}

Di Baldassarre G., \& Claps P. (2011) — A hydraulic study on the applicability of flood rating curves. Hydrol. Res. 42 : 10-19

Ibbit R. P., \& Pearson C. P. (1987) - Gauging frequency and detection of rating changes. J. Hydrol. Sci. 32 : 85-103

KiTANDIS P. K. (1984) - Effects of visitation frequency and instrument reliability on the accuracy of estimation of river discharges. J. Hydrol. Sci. 29 : 255-269

Laizé C. L. R., Marsh T. J., \& Morris D. G. (2008) - Catchment descriptors to optimize hydrometric networks. Water Manage. $161: 117-125$

Pearson C. P. (1998) - Changes in the New Zealand's national hydrometric network in the 1990s. J. Hydrol. (NZ). $37: 1-17$

Petersen-Øverleir A., Soot A., \& Reitan T. (2009) - Bayesian rating curve inference as a streamflow data quality assessment tool. Water Resour. Manage. 23 : 1835-1842

Reitan T., \& Petersen-Øverleir A. (2009) - Bayesian methods for estimating multi-segment discharge rating curves Stoch. Environ. Res. Risk Assess. 23 : 627-642

SMAKHTin V. U. (2001) - Low flow hydrology: a review. J. Hydrol. 240 : 147-186

Spence C., SAso P., \& Rausch J. (2007) - Quantifying the impact of hydrometric network reductions on regional streamflow prediction in northern Canada. Can. Water Resour. J. 32 : 1-20

Venetis C. (1970) - A note on the estimation of the parameters in logarithmic stage-discharge relationships with estimation of their error. Bull. Int. Assoc. Sci. Hydrol. 15 : 105-111 